\title{
Clinical Improvement after Surgical Debridement and Synovectomy on 4 Year Old Girl with Chronic Septic Arthritis of the Hip
}

\author{
Pamudji Utomo,,2), Denny Adriansyah",2) \\ 1)Department of Orthopaedic and Traumatology, Faculty of Medicine, \\ Universitas Sebelas Maret \\ 2)Prof DR. R. Soeharso Orthopaedic Hospital, Surakarta, Indonesia
}

\section{ABSTRACT}

Background: Incidence of septic arthritis in children less than 5 years old about 5 from 100,000 cases every year and adult above 64 years old about 8.4 cases every 100,000 people every year. The diagnosis of the chronic septic arthritis, especially in hip joint is still challenging, even for skilled doctor in musculoskeletal. Delayed diagnosis and inadequate treatment can lead to permanent joint damage and impairment.

Case presentation: In this case we discuss about clinical improvement of chronic septic arthritis in a 4 year old girl with hip pain that had been felt since 2 months before admission. Physical examination, laboratory examination, and ultrasonography examination was done and the diagnosis had been made.
Results: A surgical debridement and synovectomy was done with addition antibiotic therapy. The patient not only felt the pain was relieved but also can return into good function of hip joint.

Conclusion: Diagnosis with proper early treatment is expected to reduce permanent joint loss and improve the clinical outcome for the patient.

Keywords: septic arthritis, hip, synovectomy, surgical debridement

\section{Correspondence:}

Pamudji Utomo. Prof DR R Soeharso Orthopaedic Hospital, Pabelan, Kartasura, Surakarta, Central Java. Email: scapoid@yahoo.com.

Cite this as:

Utomo P, Adriansyah D (2020). Clinical Improvement after Surgical Debridement and Synovectomy on 4 Year Old Girl with Chronic Septic Arthritis of the Hip. Indones J Med. 05(03): 253- 258. https://doi.org/10.26911/theijmed.2020.05.03.11.

(c) (i) (-) Indonesian Journal of Medicine is licensed under a Creative Commons cc)

\section{BACKGROUND}

Incidence of septic arthritis are vary between 4-29 cases every 100,000 people every year. It was increasing to $28-38$ cases every 100,000 people every year (Gupta et al., 2001; Kaandorp et al., 1995; Mathews et al., 2010). Incidence in children less than 5 years old with septic arthritis about 5 from 100.000 cases every year and adult above 64 years old about 8.4 cases every 100.000 people every year (Gupta et al., 2001; Mathews et al., 2010).

The common sign of this condition is usually a swollen joint, but in hip joint, that sign is unlikely to be appearing. Therefore, the diagnosis can be challenging even for a skilled doctor in musculoskeletal. Sometimes, patient comes in primary care clinic or emergency-setting and the doctor in charge may lack of experience (Gupta et al., 2001; Kaandorp et al., 1995; Mathews et al., 2010).

However, Delayed and inadequate treatment can cause joint destruction and lead to limping child (Weston et al., 1999). In children with chronic cases, medication treatment usually inadequate to eradicate 
the infection, they need surgical intervention such as meticulous debridement and synovectomy (Shirtliff \& Mader, 2002; Weston et al., 1999). Total eradication of infection can promote the healing, relieve pain, and prevent relapse (Gupta et al., 2001; Mathews et al., 2010). In this case we discuss about clinical improvement in chronic septic arthritis in a girl that had been done a surgical debridement and synovectomy.

\section{CASE PRESENTATION}

A four years old girl from Surakarta, Central Java, Indonesia, went to our department with chief complain pain on the left hip since two months before admission. There was a history of trauma, she fell while running and felt pain on her left hip. After that she went to bone setter and got massaged. Patient could still be able to walk and play again. After several days' patient got a fever and pain over the left hip that aggravated by movement. Fever was relieved with antipyretic but relapse again after several hours. The temperature was $39^{\circ} \mathrm{C}$. Patient also felt loss of appetite and loss of body weight, she also refused to move her hip or walk. Patient didn't have history of other disease. Patient also didn't have any congenital or known hereditary condition. Patient was born normal breech and a term with 3200 -gram weight. Patient also growth and developed normally, she started to walk about 1 year old.

On physical examination, patient was refused to stand and walk, she also refused to move her left leg. On hip region, there was a swelling on her groin, flexion and exhortation deformity, tenderness over anterior side of the left hip. There was no neurovascular disturbance and there was no leg length discrepancy.

On pelvic $\mathrm{x}$ ray examination (Figure 1) there was an increasing on left hip joint space with irregularity on epiphyseal surface of head femur. On laboratory examination, the hemoglobin was normal $11.4 \mathrm{~g} / \mathrm{dl}$ with leucocyte blood count was 14.000 $\mathrm{u} / \mathrm{ml}$, erythrocyte sedimentation rate was $40 \mathrm{~mm} / \mathrm{s}$ and $60 \mathrm{~mm} / \mathrm{s}$, blood $\mathrm{C}$ reactive protein was positive. Patient was had an USG examination of the hip and there was an image of intra-articular fluid on the hip joint. The patient was then diagnosed with septic arthritis of the hip.

Patient had a surgical debridement and synovectomy on the left hip under consent. Patient was on general anesthesia and supine position. Incision was made 5 $\mathrm{cm}$ over bikini line between anterior superior iliac spine and inguinal. Incision was held layer by layer until graceless and Sartorius muscle and finally joint capsule. When the capsule was incised, the pus was coming out vigorously in white yellowish dusty color. Specimen for culture and pathology examination sample was taken. We debride, copious jet irrigation and synovectomy was made. The cartilage over the head femur was irregular and there was a defect to subchondral bone (Figure 2). After that, the joint capsule was sutured, drain and layer by layer sutured was done carefully. Post-operative patient was in ward, analgetic and intravenous antibiotic was given, cefazoline injection 1 gram every 8 hour for 48 hours.

After operation patient was in early mobilization and range of motion excercise. Three days after operation, surgical site wound was healed well, no sign of systemic infection or local infection. Patient then discharged on $5^{\text {th }}$ day after surgery.

\section{RESULTS}

Surgical debridement, synovectomy, and antiobiotic therapy was done for the patient. One day post-surgery, patient was informed to mobilize the hip and knee joint 
as pain as tolerated. We also checked for the wound treatment and healed well until $5^{\text {th }}$ day after surgery. Patient was able non weight bearing exercise using crutches exactly at $3^{\text {rd }}$ day after surgery and then she was discharged on $5^{\text {th }}$ day.

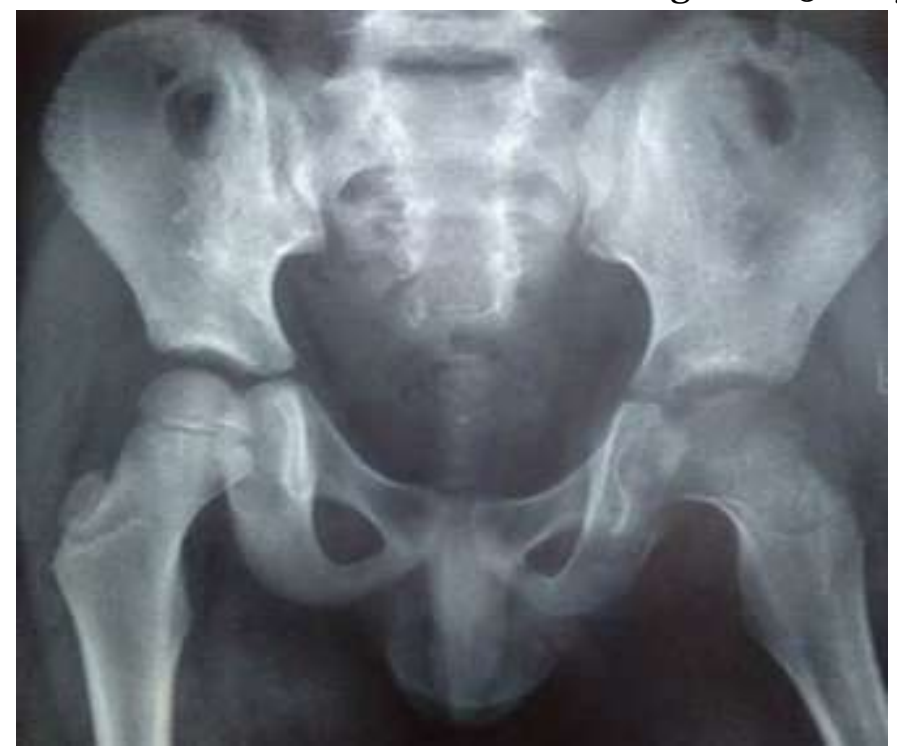

Figure 1. Pre-operative pelvis $\mathrm{x}$ ray

First week followed up the pain was much more relieve (VAS score was 1-2) and the patient could be able to partial weight bearing. She also could move her hip in range of motion about -5 to 90 degrees extension to flexion, $\mathrm{o}$ to 30 degrees adduction to abduction. On second week followed up, she could be able to move the full range of motion hip joint and partial weight bearing using one crutch. She seems to almost pain free in walking. Third week of followed up, she could full weight bearing in walking without crutches and could squat and sitting on the floor with pain free.
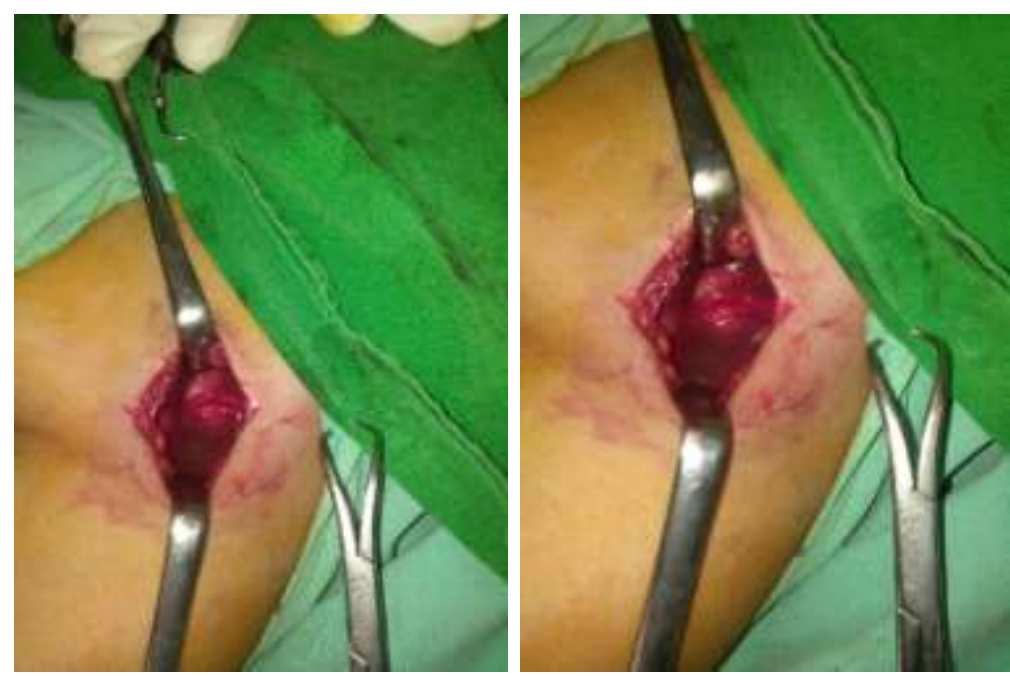

Figure 2. Intra operative, intra-articular surface was irregular with defect on cartilage, the joint space was filled with pus and blood

\section{DISCUSSION}

Complaints of septic arthritis in the form of local and systemic complaints. Classic symptoms are fever and local pain in the infected joint (Weston et al., 1999). Fever is 
the most common systemic symptom in 60$80 \%$ of cases, usually mild; high fever more than $39^{\circ} \mathrm{C}$ in $30-40 \%$ of cases (Shirtliff \& Mader, 2002; Weston et al., 1999). Pain in septic arthritis in the form of severe pain constantly at rest or active movement. Local joint pain accompanied by signs of inflammation (tumor, heat, dolor, rubor, functio laesa)(McCutchan \& Fisher, 1990; Shirtliff and Mader, 2002). Careful evaluation includes detailed history including risk factors, predisposing factors, finding sources of transient or persistent bacteremia (skin infections, pneumonia, urinary tract infections, invasive actions, injecting drug users, etc.) or joint trauma given the pathogenesis of the disease can be through local spread, inoculation direct, or hematogenous (McCutchan \& Fisher, 1990; Yang et al., 2008).

In general, patients will appear malaise and fever (McCutchan and Fisher, 1990; Shirtliff and Mader, 2002). Local physical examination must be able to distinguish inflammation caused by intraarticular or periarticular structures (such as the bursa or skin). In general, damage to intraarticular structures causes severe limitations of active or passive motion (McCutchan and Fisher, 1990; Yang et al., 2008). Swelling is found wider or diffuse and joints are often in the position of the widest intraarticular space (position of maximal intraarticular space); for example, the knee is positioned in the maximum extension position. The knee joint is most commonly affected (45-56\% of cases) followed by the hip joint (16-38\%) (Bureau et al., 1999). Polyarticular septic arthritis involving two or three joints in $10-20 \%$ of cases and is often associated with rheumatoid arthritis. Diagnosis is always based on history and physical examination that is systematic and detailed (Bureau et al., 1999; Yang et al., 2008).
Examination of leukocyte count, blood sedimentation rate, and C-reactive protein (CRP) are useful for detecting infectious or inflammatory processes, but are not specific. If increased, these markers can be used to monitor the therapeutic response. Blood cultures can be positive in 25-50\% of cases(Bureau et al., 1999; McCutchan and Fisher, 1990; Yang et al., 2008).

Ultrasonography is sensitive for detecting joint effusion (1-2 $\mathrm{mL}$ ), widening more than $2 \mathrm{~mm}$ between joint and bone capsules is a marker of effusion, can be echo-free (possibly transient synovitis) or hyperechoic (more likely septic arthritis) (Bureau et al., 1999; Ross, 2005). Plain xrays are usually within normal limits. Some things that can be evaluated from plain photographs are soft tissue swelling, widening of the joint gap, and mild subluxation (due to joint fluid). Sometimes E. coli infection produces gas in the joints (Bureau et al., 1999; Yang et al., 2008). Narrowing and irregularity in joint gaps are further features of septic arthritis. Magnetic resonances imaging (MRI) and radio nuclear can help diagnose arthritis in difficult places (Bureau et al., 1999; Ross, 2005).

The main management is in the form of antibiotics and evacuation of pus. No randomized controlled trial has been found for the selection and duration of antibiotics (Ravindran et al., 2009; Sammer \& Shin, 2009). A systematic review and metaanalysis showed no difference in clinical and bacteriological effects between one antibiotic regimen and another (Bureau et al., 1999; Ravindran et al., 2009; Sammer and Shin, 2009). The choice of empirical antibiotics depends on the clinical picture, patient risk factors, and germ prevalence patterns (Butt et al., 2011; Sammer \& Shin, 2009; Shirtliff and Mader, 2002). In 
patients at high risk of sexually transmitted diseases and staining of aspirate joints showing negative ram, ceftriaxone can be combined with azithromycin or doxycycline for eradication of Gonococcus and Chlamydia infections. If the patient is not clear of a high risk of sexually transmitted diseases or negative ram, ceftriaxone can be combined with vancomycin (Butt et al., 2011; Sammer \& Shin, 2009).

In the acute phase, patients are advised to rest the affected joints. Rehabilitation is important to maintain joint function and reduce septic arthritis morbiddity. Rehabilitation should have been done when arthritis appeared to reduce loss of function. In the acute phase, patients tend to maintain joint position which can facilitate complications of joint contractures. Splinting is sometimes necessary to maintain a position with optimal function; knee joints with extension position, pelvic joints balanced position extension and neutral rotation, elbow flexion $90^{\circ}$, and wrist position neutral to slight extension (Butt et al., 2011; Ross, 2005). In the acute phase, isotonic muscle contraction exercises must be done immediately to prevent muscle atrophy. Active and passive joint movements must be done immediately within 24 hours after the complaint improves (Butt et al., 2011; Ross, 2005).

The prognosis of septic arthritis depends on host factors, virulence of infectious agents, and the speed of adequate therapy (Kaandorp et al., 1997). The main morbidity is a significant decrease in joint function although treated appropriately; $50 \%$ of adults show sequelae decreasing ROM or chronic pain. In the study of Kaandorp et al. found $33 \%$ of cases with poor joint outcome, namely amputation, arthrodesis, prosthetic surgery, or severe functional deterioration, mortality 2-14\% (Kaandorp et al., 1997).
Predictors of adverse outcomes were (1) age $>60$ years, (2) pelvic or shoulder joint infections, (3) accompanied by rheumatoid arthritis, (4) culture of joint aspiration was still positive after adequate antibiotic administration for 7 days, (5) delay of therapy during 7 days or more (Butt et al., 2011; Kaandorp et al., 1997). For the conclusions, septic arthritis is a diagnosis of acute monoarticular arthritis. Failure to provide appropriate antibiotic therapy within 24 to 48 hours can cause subchondral bone damage and permanent joint dysfunction. Diagnosis with proper early treatment is expected to reduce permanent joint loss and improve the clinical outcome for the patient.

\section{PATIENT CONSENT}

This study had obtained patient approval and informed consent for study and publication.

\section{AUTHOR CONTRIBUTIONS}

Pamudji Utomo and Denny Adriansyah were contribute the same and equally in developing, analyzing, and preparing the manuscript to report the research results

\section{CONFLICT OF INTEREST}

There was no conflict of interest in this study.

\section{FUNDING AND SPONSORSHIP}

There was no funding or sponsorship in this study.

\section{ACKNOWLEDGEMENT}

We give our gratitude to Orthopaedic hospital Prof R. Soeharso Surakarta who permitted us to done our study.

\section{REFERENCE}

Bureau NJ, Chhem RK, Cardinal É (1999). Musculoskeletal infections: US mani- 
Utomo et al./ Clinical Improvement after Surgical Debridement

festations. Radiographics, 19(6), 1585-1592. https://doi.org/10.1148/radiographics.19.6.g99noo61585.

Butt U, Amissah-Arthur M, Khattak F, Elsworth CF (2011). What are we doing about septic arthritis? A survey of UK-based rheumatologists and orthopedic surgeons. Clinical Rheumatology, 30(5): 707-710. https://doi.org/10.1007/s10067-010-1672-3.

Gupta MN, Sturrock RD, Field M (2001). A prospective 2-year study of 75 patients with adult-onset septic arthritis. Rheumatology, 40(1): 24-30. https://doi.org/10.1093/rheumatology/40. 1.24 .

Kaandorp CJ, Van Schaardenburg D, Krijnen P, Habbema JD, van de Laar MA (1995). Risk factors for septic arthritis in patients with joint disease. A prospective study. Arthritis Rheum. 38(12): 1819-25. https://doi.org/10.1002/art.1780381215.

Kaandorp CJ, Dinant HJ, van de Laar MA, Moens HJ, Prins AP, Dijkmans BA (1997). Incidence and sources of native and prosthetic joint infection: A community based prospective survey. Ann Rheum Dis. 56(8): 470-475. https://doi.org/10.1136/ard.56.8.470.

Mathews CJ, Weston VC, Jones A, Field M, Coakley G (2010). Bacterial septic arthritis in adults. The Lancet, 375 (9717): 846-855. https://doi.org/10.1016/So140-6736(09)61595-6.

McCutchan HJ, Fisher RC (1990). Synovial leukocytosis in infectious arthritis. Clinical Orthopaedics and Related Research. 257: 226-230. https://doi.org/10.1097/ooo03086-19900800000037 .
Ravindran V, Logan I, Bourke BE (2009). Medical vs surgical treatment for the native joint in septic arthritis: A 6year, single UK academic centre experience. Rheumatology (Oxford, England), 48(10): 1320-1322. https://doi.org/10.1093/rheumatology/kep220.

Ross JJ (2005). Septic arthritis. Infectious Disease Clinics of North America, 19(4): 799-817. https://doi.org/10.1016/j.idc.2005.07.004

Sammer DM, Shin AY (2009). Comparison of arthroscopic and open treatment of septic arthritis of the wrist. Journal of Bone and Joint Surgery - Series A, 91(6): 1387-1393. https://doi.org/10.2106/JBJS.H.00630.

Shirtliff ME, Mader JT (2002). Acute septic arthtritis. Clinical Microbiology Reviews. 15 (4): 527-544; Doi: 10.1128/CMR.15.4.527-544.2002.

Weston VC, Jones AC, Bradbury N, Fawthrop F, Doherty M (1999). Clinical features and outcome of septic arthritis in a single UK Health District 19821991. Annals of the Rheumatic Diseases. 58(4): 214-219. https://doi.org/10.1136/ard.58.4.214.

Yang S, Ramachandran P, Hardick A, Hsieh YH, Quianzon C, Kuroki M, Hardick $\mathrm{J}$, et al. (2008). Rapid PCR-based diagnosis of septic arthritis by early gram-type classification and pathogen identification. J Clin Microbiol. 46(4): 1386-1390. https://doi.org/10.1128/JCM.02305-07. 